\title{
Single Crystal Organic Photovoltaic Cells
}

\author{
Masahiro Hiramoto* and Mitsuru Kikuchi \\ National Institutes of Natural Sciences, Institute for Molecular Science, Japan
}

*Corresponding author: Masahiro Hiramoto, National Institutes of Natural Sciences, Institute for Molecular Science, Japan, Tel: +81-564-59-5537; Email: hiramoto@ims.ac.jp

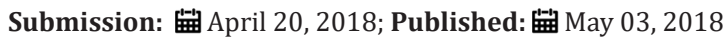

Keywords: Organic single crystals; Lateral electron transports; Ranges; Mobilities; NTCDA

\section{Mini Review}

Carrier mobilities of organic single crystals reached greater than $10 \mathrm{~cm}^{2} \mathrm{~V}^{-1} \mathrm{~s}-1[1,2]$. Such high mobility was observed for carriers moving laterally through the material due to $\pi-\pi$ stacking parallel to the crystal surface. Conventional organic solar cells are built vertically on indium tin oxide (ITO) glass substrates with a sandwich-type structure [3-6]. However, the thickness of such solar cells with blended layers of donor (D) and acceptor (A) molecules, which are indispensable to dissociate excitons, is limited to just around $100 \mathrm{~nm}$ due to the problem of carrier collection arising from imperfections in the electron and hole transport routes in the blended layer. If the photogenerated electrons and holes can be transported laterally and collected, we can be freed from the vertical transport of carriers and freed from the limitation to the vertical thickness of the cell.

The concept of the lateral type cell is shown in Figure 1a. Electrons move laterally through the single crystal substrate. A pair of electrodes separated by a distance $\mathrm{L}$ is deposited in parallel on the crystal surface. A layer of organic semiconductor acting as a donor (DBP) is inserted between the organic single crystal (NTCDA) substrate, which acts as an acceptor. At the D/A interface, excitons dissociate into electrons and holes under light irradiation. Since the photogenerated holes move in the vertical direction, the distance to the electrode is equal to the film thickness of $30 \mathrm{~nm}$. On the other hand, since the photogenerated electrons move laterally, the inter-electrode distance (L) is at least $30 \mu \mathrm{m}$. Thus, the lateral distance is 1000 times the vertical distance, which means that the cell characteristics are dominated by the electron transport. The right hand edge of the hole collection electrode can be regarded as the starting point for the electrons (broken blue line). The range of the electrons $\left(\mathrm{L}_{\mathrm{e}}\right)$ is expressed by eq. (1).

$$
L_{e}=\mu_{e} \tau_{e} E
$$

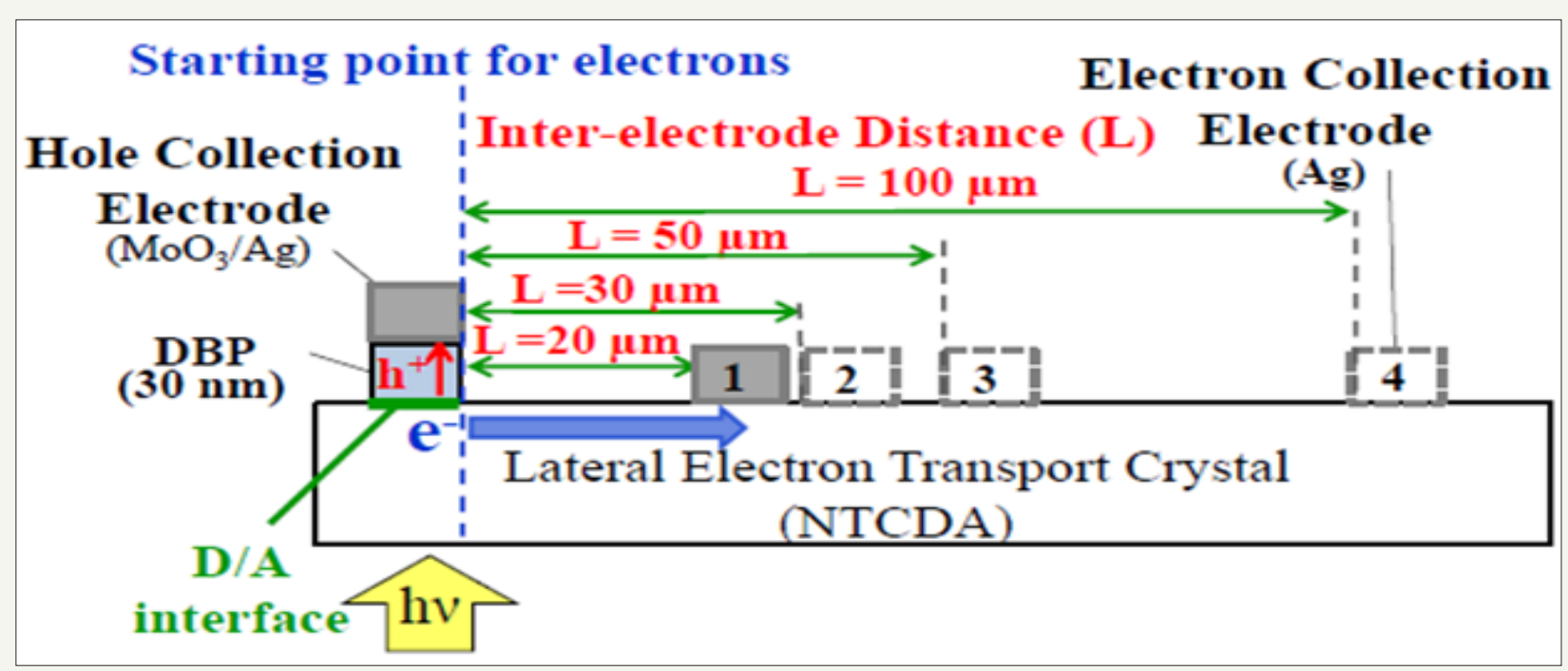

Figure 1a: Configurations of the lateral organic single crystal cell. 
Where $\mu_{e}, \tau_{e}$ and $\mathrm{E}$ are the electron mobility, the electron lifetime, and the electric field, respectively. The inter-electrode distance $L$ can be varied (Figure 1a). When $L$ is within the range Le $\left(\mathrm{L}_{\mathrm{e}}>\mathrm{L}\right)$ the electrons can be collected at the electrode, but when it is not $\left(\mathrm{L}_{\mathrm{e}}<\mathrm{L}\right)$ they cannot. So, the photocurrent decreases when $\mathrm{L}$ is at around $\mathrm{L}_{\mathrm{e}}$. In this mini-review, we describe lateral electron transport and electron collection in organic photovoltaic cells using NTCDA single crystal (Figure 1b).

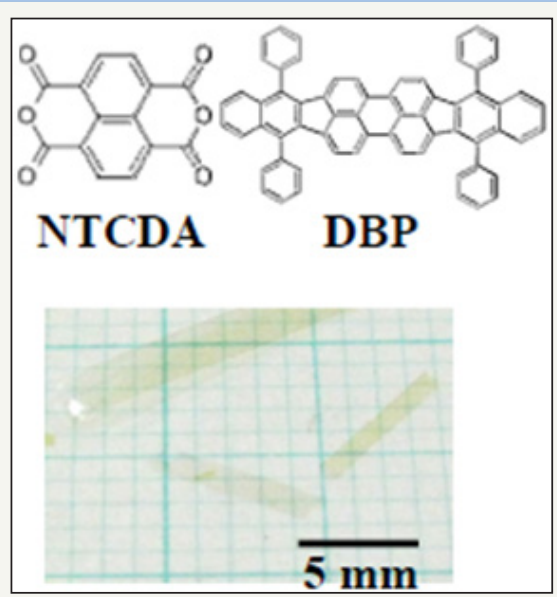

Figure 1b : Chemical structures of NTCDA and DBP. A photograph of NTCDA single crystal is also shown.

Figure $2 \mathrm{a}$ shows the current-voltage (J-V) characteristics of cells with $\mathrm{L}=20,30,50,100 \mu \mathrm{m}$ under irradiation of 10 suns. When L increases from 20 (orange curve A) to $30 \mu \mathrm{m}$ (red curve $B)$, the magnitudes of photocurrents in the saturated region of reverse direction from -1 to $-3 \mathrm{~V}$ coincided well. When $\mathrm{L}$ increases from 30 (red curve B) to $50 \mu \mathrm{m}$ (blue curve $\mathrm{C}$ ), the photocurrent decreases significantly. A further increase of $L$ from 50 (blue curve C) to $100 \mu \mathrm{m}$ (green curve D) causes a further, moderate decrease in photocurrent. This result suggests that the effective electron transport occurred within $30 \mu \mathrm{m}$ in the lateral direction, i.e., the electron range $\left(\mathrm{L}_{\mathrm{e}}\right)$ was around $30 \mu \mathrm{m}$.

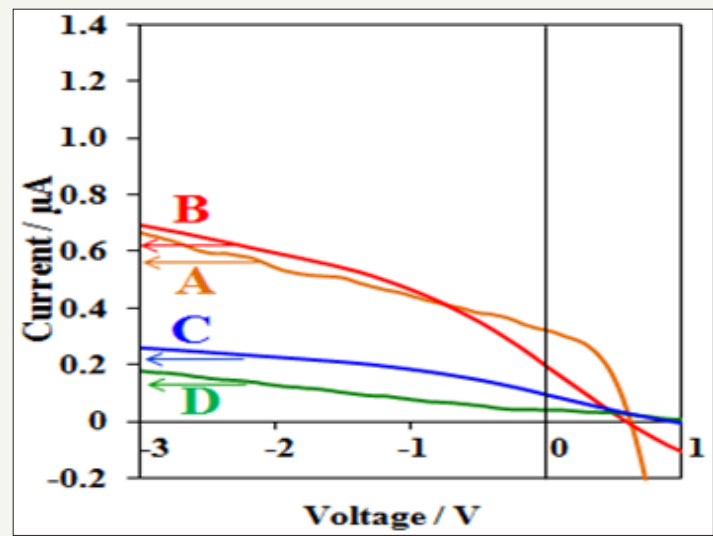

Figure 2a: $J-V$ characteristics of lateral cells with $\mathrm{L}=20 \mu \mathrm{m}$

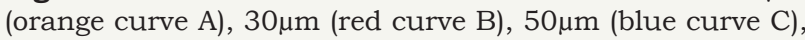
and $100 \mu \mathrm{m}$ (green curve D) under irradiation of 10 suns.

In Figure 2b, the photocurrent-L relationships at constant values of $\mathrm{E}$ of $1,2,3,4$, and $5 \times 102 \mathrm{Vcm}^{-1}$, which are around the magnitude of the built-in field $\left(2 \times 102 \mathrm{~V} \mathrm{~cm}^{-1}\right)$. Again, sharp decreases in photocurrent were confirmed between $\mathrm{L}=30$ and $50 \mu \mathrm{m}$. Photocurrent was almost constant below $\mathrm{L}=30 \mu \mathrm{m}$ under the sufficient electric fields (green dots C, blue dots D, purple dots E). Therefore, we concluded that the electron range $\left(\mathrm{L}_{\mathrm{e}}\right)$ is around $30 \mu \mathrm{m}$.

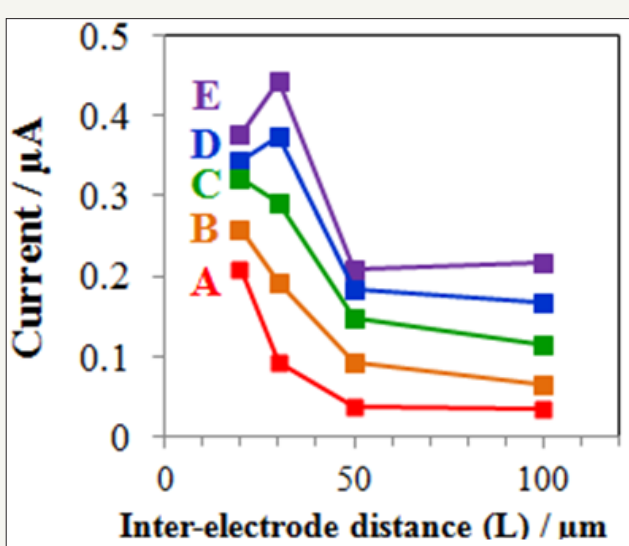

Figure 2b: Dependence of the photocurrent on $\mathrm{L}$ at constant values of $\mathrm{E}$ of $1 \times 10^{2}$ (red dots $\mathrm{A}$ ), $2 \times 10^{2}$ (orange dots $\mathrm{B}$ ), $3 \times 10^{2}$ (green dots C), $4 \times 10^{2}$ (blue dots D), and $5 \times 10^{2} \mathrm{Vcm}^{-1}$ (purple dots E).

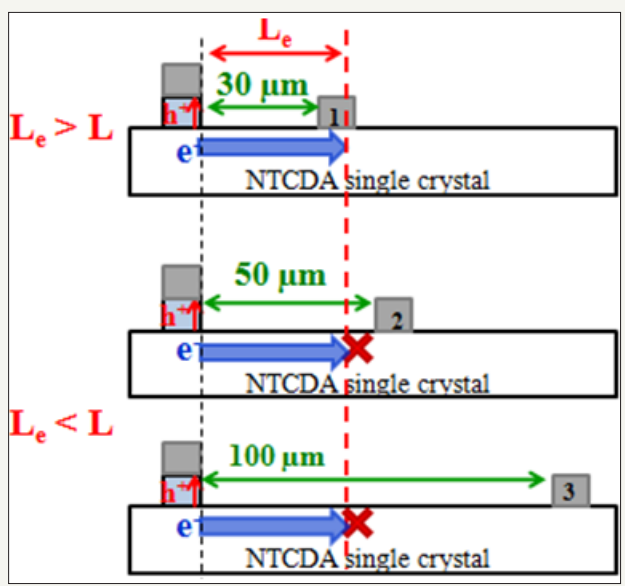

Figure 2c: Schematic illustrations of the relationship between $\mathrm{L}$ and $\mathrm{L}_{\mathrm{e}}$ in the lateral cells.

Figure 2c shows schematic illustrations of lateral cells with $\mathrm{L}=30,50$, and $100 \mu \mathrm{m}$. Le is $30 \mu \mathrm{m}$. When $\mathrm{L}_{e}<\mathrm{L}$, a small number of electrons can reach the collection electrode. This situation is realized for $\mathrm{L}=50$ (Figure 2c, middle) and $100 \mu \mathrm{m}$ (Figure 2c, bottom). When $\mathrm{L}_{\mathrm{e}}>\mathrm{L}$, most of the electrons can reach the collection electrode. This situation is realized for $\mathrm{L}=30 \mu \mathrm{m}$ (Figure. 2c, top).

By eq. (1), electron lifetime $\tau_{e}$ was calculated to be $0.52 \mathrm{~ms}$. The electron mobility $\mu_{e}$ of the NTCDA single crystal was $2.9 \times 10$ $2 \mathrm{~cm}^{2} \mathrm{~V}^{-1} \mathrm{~s}^{-1}$. The value of $\tau_{e}$ obtained $(0.52 \mathrm{~ms})$ is of the order of milliseconds, and would enable an electron range $L_{e}$ of the order of millimeters to be obtained if single crystal organic materials with an electron mobility $\mu_{e}$ of $1 \mathrm{~cm}^{2} \mathrm{~V}^{-1} \mathrm{~s}^{-1}$ were used [2].

The operation of a single crystal organic photovoltaic cell was demonstrated. An electron range $\left(\mathrm{L}_{\mathrm{e}}\right)$ reached $30 \mu \mathrm{m}$. The large value 
of $\tau_{e}$ close to the order of a millisecond indicates the possibility of having electron ranges of the order of millimeters. Near future, we would be freed from the vertical transport of carriers and freed from the limitation to the vertical thickness of the organic solar cell.

\section{References}

1. Takeya J, Yamagishi M, Tominari Y, Hirahara R, Nakazawa Y, et al. (2007) $\mathrm{AlAs} / \mathrm{GaAs}$ micropillar cavities with quality factors exceeding 150.000 . Appl Phys Lett 90: 1021120.

2. Chesterfield RJ, McKeen JC, Newman CR, Ewbank PC, Filho DA, et al. (2004) rganic Thin Film Transistors Based on N-Alkyl Perylene Diimides: Charge Transport Kinetics as a Function of Gate Voltage and Temperature. J Phys Chem 108 (50): 19281-19292.
3. Hiramoto M, (2017) Organic Solar Cells, In: Kasap S \& Capper P (Eds.) Part E Novel Materials and Selected Applications, Springer Handbook of Electronic and Photonic Materials ( $\left.2^{\text {nd }} e d n\right)$, Springer International Publishing AG, Switzerland, pp. 1239-1338.

4. Hiramoto M (2017) Energetic and nanostructural design of smallmolecular-type organic solar cells, In: Rice SA \& Dinner AR (Eds.), Advances in Chemical Physics, John Wiley \& Sons, USA, pp. 137-204.

5. Tang CW (1986) Two-layer organic photovoltaic cell. Appl Phys Lett 48: 183.

6. Hiramoto M, Fujiwara H, Yokoyama M (1991) Three-layered organic solar cell with a photoactive interlayer of codeposited pigments. Appl Phys Lett 58: 1062.
Creative Commons Attribution 4.0 International License

For possible submissions Click Here

\section{Submit Article}

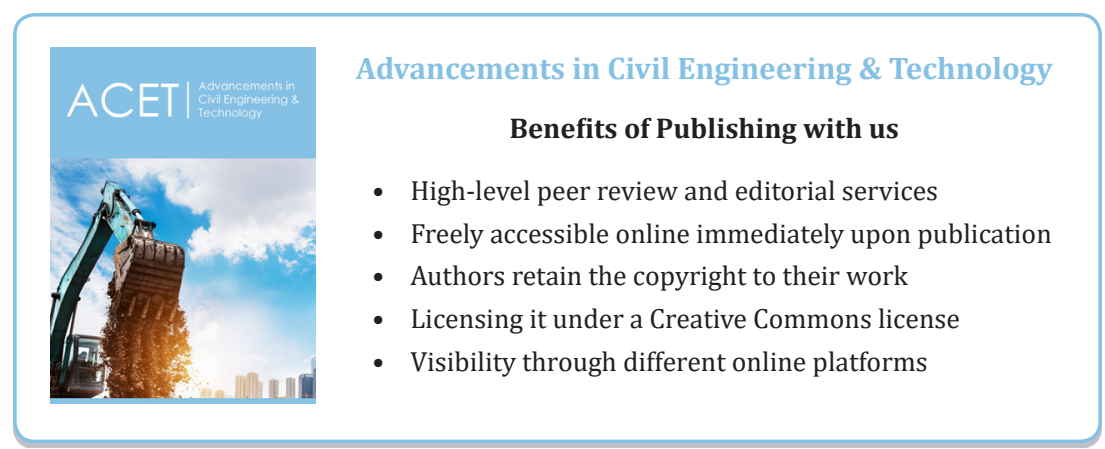

